\section{Derivatives of Caffeic Acid in Sweet Potato attacked by Black Rot}

Several polyphenols have been found to be accumulated in the sound part next to the injured tissues of sweet potato attacked by black rot caused by Ceratostomella fimbriata, and chlorogenic acid, caffeic acid and isochlorogenic acid have been isolated as well as the two kinds of new caffeic acid derivatives. Previously, G. O. Rudkin and J. M. Nelson ${ }^{1}$ had isolated chlorogenic acid and a group of components giving caffeic acid by alkaline hydrolysis from sound sweet potato.

Extraction and fractionation of the material were carried out chiefly by the method of Rudkin and Nelson. Sound tissues taken from sweet potato suffering from black rot were extracted with acetone, polyphenols in the extract were converted to the lead salts, which were decomposed with dilute sulphuric acid, and the resulting solution was shaken with ethyl acetate; from the ethyl acetate layer (upper) crude polyphenols were separated. These crude polyphenols were dissolved in phosphate buffer $(p \mathrm{H} 4 \cdot 7)$ and shaken with an equal volume of ethyl acetate; the buffer layer (lower) was adjusted to $p \mathrm{H} 2 \cdot 0$ and shaken with ethyl acetate, the ethyl acetate was concentrated and the crystalline chlorogenic acid (m.p. 205-6 ${ }^{\circ}$ ) was obtained by adding chloroform to it.

The remainder of the ethyl acetate layer, separated from the buffer layer, was concentrated, and, by adding petroleum ether gradually, polyphenols in this layer were divided into two parts, which were quickly precipitated and slowly precipitated respectively. From the latter caffeic acid (m.p. 192-94 ${ }^{\circ}$ ) was removed as crystals. The former was subjected to 44-transfer counter-eurrent distribution using phosphate buffer $(p H \mathbf{H} \cdot 8)$ and ethyl acetate as solvents. As the result, it was divided into three fractions, $A$, $B, C$, having partition coefficients $0.48,1 \cdot 36$ and greater than 40 respectively. $A$ and $B$ were collected and again subjected to counter-current distribution. They gave curves corresponding with the theoretical curve, proving their freedom from impurity; but they have not been crystallized in the free form and derivatives have not been prepared. It is not known whether $C$, a white powder, is a single polyphenol or not.

$A, B$ and $C$ were decomposed with alkali, and separa. ted in crystals into caffeic acid (yield 100 per cent each) and quinic acid (60 per cent each). Each caffeic acid was identified by mixed melting point $\left(192-94^{\circ}\right)$ and elementary analysis, further confirmed by those of methyl caffeate derived from it. Each quinic acid was also identified by mixed melting point $\left(168-69^{\circ}\right)$ and elementary analysis of its brucine salt.

The ultra-violet absorption spectra of $A, B$ and $C$ were almost the same as that of chlorogenic acid. Infra-red absorption spectra of $A$ and $B$ were very similar, but they were different from that of chlorogenic acid, while that of $C$ was not like either of them. The optical rotations of $A, B$ and $C$ were $[\alpha]_{D}^{13}-155^{\circ},[\alpha]_{D}^{13}-196^{\circ}$, and $[\alpha]_{D}^{13}-94^{\circ}$; and the neutral equivalents of $A$ and $B$ were 586 and 563 respectively; $C$ had a large value and seemed a polymer. The properties of $B$ were similar to those of isochlorogenic acid $\left([\alpha]_{D}^{20}-230^{\circ}\right.$, neutral equivalent c. 580 , rate of oxidation by periodic acid, etc.) isolated from coffee beans and investigated by $\mathrm{H}$. M. Barnes and W. V. White ${ }^{2}$. We also attempted to separate isochlorogenic acid from coffee according to the method of Barnes and White, and the acid was subjected to counter-current distribution; the distribution curve was in accordance with that of $B$. Thus $B$ was identified as isochlorogenic acid. The lower rotation value of $B$ compared with Barnes's might be due either to the different conditions of measurement (rotation was measured at 1 per cent concentration in alcohol solution using a 1-decimetre tube) or to traces of impurity. We have been informed by J. Corse (private communication) that he has isolated isochlorogenic acid from dehydrated sweet potato.

The properties of $A$ and $B$ are very alike, except for different values in the rotation, partition coefficient, and solubility in ethyl acetate. $A$ was found to be present with $B$ in the black-rot tissue of sweet potato; but it might be derived from $B$ or some other component during isolation. Tentatively, we propose to call $A$ pseudochlorogenic acid. We are considering the position of linkage of the caffeic acid with quinic acid. We could obtain no evidence for the presence in the sound part next to the injured tissues of sweet potato of neochlorogenic acid recently isolated by J. Corse ${ }^{3}$ from peaches.

We thank Prof. Y. Sumiki and Prof. S. Funahashi, of Tokyo University, and Dr. William V. White, of the General Food Corporation, U.S.A., for their advice, and Dr. J. Corse, of the U.S. Agricultural Research Service, for information and a present of neochlorogenic acid.

IKUZO URITANI Masateru Miyano

Laboratory of Biochemistry,

Faculty of Agriculture,

Nagoya University, Anjo, Japan.

$$
\text { Dec. } 8 .
$$

${ }^{1}$ Ruđkin, G. O., and Nelson, J. M., J. Amer. Chem. Soc., 69, 1470 (1947).

${ }^{2}$ Barnes, H. M., and White, W. V., J. Amer. Chem. Soc., 72, 4178 (1950).

${ }^{3}$ Corse, J., Nature, 172, 772 (1953).

\section{Development of Anopheles A Virus in the Endoplasmic Reticulum of Ehrlich Ascites Tumour Cells}

EHRLICH ascites tumour grown as a free cell suspension in the abdominal cavity of mice was inoculated with a mosquito-borne virus, anopheles $A{ }^{1,2}$, usually propagated in the brain tissue of mice. Some destruction of tumour cells occurred within 5-6 days.

Particles believed to be the virus were identified within tumour cells by electron microscopic examins. tion of ultra-thin sections. As in the case of other viruses studied in thin section ${ }^{3-5}$, this virus also shows internal structure, here consisting of a transparent $\sim 30 \mathrm{~m} \mu$ core, and a compound electron-opaque shell, $12 \mathrm{~m} \mu$ thick, giving a total diameter of approximately $55 \mathrm{~m} \mu$. (Although the size of anopheles $A$ virus has been reported to be larger than $55 \mathrm{~m} \mu^{6}$, recent studies with ionizing radiation by $\mathrm{E}$. Pollard and R. A. Brown indicate a particle-size considerably smaller than that determined by ultrafiltration.) Detailed study of viral foci in serial sections showed them to be localized within what has been variously referred to as the endoplasmic reticulum? ${ }^{7}$, ergasto- 